Ind. Health, 1969, 7, 139.

\title{
DIAGNOSTIC PROVOCATION TEST FOR WHITE FINGER ATTACKS BY WATER BATH IN CHAIN SAW OPERATORS
}

\author{
Ichiro WAKISAKA, Masami TOGO and Kyoko TAKAMOTO \\ Department of Public Health, Faculty of Medicine, \\ Kagoshima University, Shiroyamacho, Kagoshima
}

(Received October 13, 1969)

\begin{abstract}
A new method of provocation test of white finger attacks in chain saw operators was designed. It consists of $i$ ) bath of body in $24^{\circ} \mathrm{C}$ water for $10 \mathrm{~min}$, usually in a bathtub and ii) immersion of hands in $4^{\circ} \mathrm{C}$ water for 1 min. Fifteen chain saw operators were examined by this method and a good result was obtained. The inconsistencies between the complaints of the subjects and the results of provocation test suggest the importance of periodical examination of all chain saw operators with provocation test.
\end{abstract}

If one can provoke white finger attacks without any lapse of cases, it will be an essential test for diagnosis of Raynaud's phenomenon of occupational origin. Hitherto, the diagnosis of Raynaud's phenomenon has been based on spontaneous development of the attacks or complaint itself by patients except a few trials of provocation.

Many attempts to find out some differences in skin temperatures with or without cold stress on the silent period of the attacks, have succeeded in obtaining only suggestive data for the diagnosis of Raynaud's phenomenon.

Okada et $a l .{ }^{1 /}$ have succeeded in provocation of the attacks in about $80 \%$ of chain saw operators who complained of the attacks. The attacks were provoked by immersion of hands in $4^{\circ} \mathrm{C}$ water in a temperature-controlled room at $6^{\circ} \mathrm{C}$.

We also attempted to provoke the attacks for diagnosis of Raynaud's phenomenon in chain saw operators in summer. We adopted a new method of provocation test and obtained good results in applying it to the subjects. The method is very simple and inexpensive. Any special technique, apparatus or even temperaturecontrolled room is not required.

\section{Method}

The method consists of two procedures as follows;

Procedure 1: Bath of body in $24^{\circ} \mathrm{C}$ water for $10 \mathrm{~min}$, usually in a bathtub. Procedure 2: Immersion of hands in $4^{\circ} \mathrm{C}$ water for $1 \mathrm{~min}$. 


\section{WAKISAKA, M. TOGO AND K. TAKAMOTO}

If a bathtub is not available, we use a children's swimming pool made of vinyl sheet ( $1750 \mathrm{~mm}$ in diameter and $370 \mathrm{~mm}$ in depth) instead of a bathtub.

Procedure 2 is applied immediately after Procedure 1 . If the attacks are provoked by procedure 1 , procedure 2 is not applied.

We carried out the provocation test at room temperature which was always above $25^{\circ} \mathrm{C}$. Physical examinations such as auscultation of heart sound and measurement of blood pressure of subjects preceded provocation test and the subjects were supervised by physicians during provocation test for prevention of accidents. Subjects

We examined 15 chain saw operators. Their complaints were as follows;

(A) 9 subjects complained of manifest white finger attacks,

(B) 4 subjects complained of indistinct white finger attacks and

(C) 2 subjects complained of no white finger attack.

Capital letters in parentheses correspond to columns of Table 1. When and how frequently the attacks developed was put out of the question.

\section{Results}

We observed in the provocation test as follows;

(1) manifest white finger attacks in 9 subjects,

(2) indistinct white finger attacks in 3 subjects and

(3) no pathologic finding in 3 subjects.

Numbers in parentheses correspond to rows of Table 1. "Indistinct" white finger attacks mean not manifest but somewhat paler fingers than other region of the same finger or other fingers of the same subjects and this kind of the attacks disappear sooner than manifest ones.

Relationship between the complaints of the subjects and the results of provocation tests are shown in Table 1.

Table 1. Results of provocation test and its relationship to the complaints of subjects.

\begin{tabular}{l|ccc|c}
\hline \multirow{2}{*}{ Results } & \multicolumn{3}{|c|}{ Complaints } & \multirow{2}{*}{ Total } \\
\cline { 2 - 6 } & (A) Manifest & (B) Indistinct & (C) None & (C) \\
\hline (1) Manifest & 9 & 0 & 0 & 9 \\
(2) Indistinct & 0 & 2 & 1 & 3 \\
(3) None & 0 & 2 & 1 & 3 \\
\hline \multicolumn{1}{r|}{ Total } & 9 & 4 & 2 & 15 \\
\hline
\end{tabular}

In 12 subjects, i. e., 9 subjects of column (A), row (1) ((A)-(1)), 2 subjects of (B)-(2) and 1 subject of (C)-(3), the complaints correspond to the results of provocation test. In 2 subjects of (B)-(3), who complained of the attacks, we could not confirm their complaints. In 1 subject of (C)-(2), who did not complain, we observed the attack. 


\section{PROVOCATION TEST FOR WHITE FINGER ATTACKS}

\section{Discussion}

Owing to the present method, white finger attacks were provoked easily without giving subjects any severe pain or stress. It has made easier the objective diagnosis of Raynaud's phenomenon.

It is said that cooling of whole body is more effective to provoke the attacks than cooling of hands alone. Procedure 1 plays a significant role in provocation test. Procedure 2 alone scarcely succeeded in provoking the attacks.

In a few cases, the attacks were provoked by Procedure 1 alone, and in many other cases, Procedure 1 was followed by Procedure 2. We think that Procedure 2 also plays a significant role when it follows Procedure 1.

The conditions of provocation test, for example, time, temperature and interval between Procedure 1 and 2, should be examined furthermore. It may be effective to apply both procedures simultaneously.

Body composition of subjects should also be considered in regard to sensitivity to cold stress. But practically, the conditions we adopted are effective enough to provoke the attacks.

We set up two criteria to evaluate severity of the attacks. Manifest attack is severer than indistinct one. An attack which is provoked by Procedure 1 is severer than which is provoked by both Procedure 1 and 2 . The first criterion has priority over the second criterion. In this way, it will be able to follow up the course of Raynaud's phenomenon roughly but objectively all the year round.

We found two kinds of inconsistencies between the complaints of subjects and the results of provocation test. These inconsistencies exist in the case of (B)-(3) and $(\mathrm{C}) \cdot(2)$.

1. We suppose that there are some possible reasons why the inconsistency of (B)-(3) (subjects complain of attacks but no attack is provoked) occurs.

a) We believe that the attacks certainly developed in the past as subjects claimed. They had not used chain saw since then and recently the attacks had not developed spontaneously and no attack appeared in provocation test. It is likely that Raynaud's phenomenon of these subjects had almost recovered and therefore we could not provoke the attacks in them.

b) It is also likely that Raynaud's phenomenon was at early stage and its symptoms were so slight that we could not observe the attacks in the provocation test. The subjects might have experienced the attacks in extremely cold weather. If the conditions of provocation test were severer, for instance, bath in water at lower temperature than $24^{\circ} \mathrm{C}$ and / or for longer time than $10 \mathrm{~min}$, immersion of hands in $4^{\circ} \mathrm{C}$ (or higher temperature if not tolerable) water for longer time than $1 \mathrm{~min}$, the attacks might be provoked. But provocation test with such severe conditions give subjects pain and stress, so that we gave up the attempt to provoke the attacks.

c) If subjects were very anxious about their health, they might mistake 


\section{WAKISAKA, M. TOGO AND K. TAKAMOTO}

change of finger colour which had no pathologic meaning for white finger attacks. But we could not decide whether their complaint was true or false.

2. And we suppose that there are some possible reasons why the inconsistency of (C)-(2) (subjects complain of no attack but the attacks are provoked) occurs.

a) Because white finger attacks develop spontaneously only in winter, the first time the patients recognize the attacks is also in winter. If Raynaud's phenomenon advanced to the stage at which the attacks began to develop before or in last winter, it could be recognized in last winter. If it advanced to the same stage after last winter, e. g., in this summer, the attacks do not develop unless they are provoked, and it will not be recognized until next winter. The subjects with Raynaud's phenomenon of this stage of course do not complain of any attack but the attacks can be provoked even in summer.

b) There is difference of carefulness to recognize an indistinct attack among individuals. If the attacks of the same grade develop among them, some subjects who are careful enough to recognize the attacks, will complain of them and the other subjects, who are not so careful, will not complain of them.

Okada et al. ${ }^{11}$ reported that they provoked the attacks which had not been recognized by the patient himself.

These inconsistencies suggest that all chain saw operators should be examined with provocation test periodically.

\section{REFERENCE}

1) Okada, A., Yamashita, T. and Ueda, M. (1967). Japan. J. Ind. Health, 9, 51. 